\title{
El paisaje como elemento integrador de fenómenos geográficos
}

\author{
Javier Lozano Parra
}

La percepción y el concepto de paisaje han evolucionado paralelamente a lo largo del tiempo, desde sus contenidos pictóricos, artísticos o literarios hasta su consideración holística actual, como unidad o elemento integrador de los componentes bióticos, abióticos y antrópicos. Dichos componentes interaccionan entre sí dentro del paisaje determinando los flujos de materia y energía. El fundamento básico de la geografía es llegar al conocimiento total de estos componentes: captar la realidad con todas sus interrelaciones y con todas sus dinámicas. La finalidad es ambiciosa, un correcto entendimiento los componentes del paisaje y de sus interrelaciones permitirá resolver los problemas con dimensión espacial, es decir, los problemas geográficos. Por ello, este número 72 de Revista de Geografía Norte Grande pretende destacar la importancia del estudio del paisaje como elemento integrador de fenómenos geográficos, con el propósito de entender de forma más precisa la realidad que nos rodea.

Con el paisaje como principal componente geográfico, el trabajo de Alejando Sepúlveda-Varas, Pablo Saavedra Briones y Carlos Esse analiza la dinámica de cambio de cobertura y uso de suelo para una subcuenca hidrográfica ubicada en la región de La Araucanía (Chile) durante el periodo 1994-2007. Para ello, desarrollan un análisis cartográfico y aplican diferentes estadísticos que les permiten identificar áreas sometidas a mayor presión de uso, como los cultivos-praderas naturales y las plantaciones forestales. Los autores observaron que dichas áreas concentraron el $79,5 \%$ de la superficie total del cambio neto en la subcuenca, y reafirman la necesidad de analizar la evolución en el uso del suelo previo a la identificación de las potencialidades del recurso suelo para soportar nuevas actividades productivas.

En esta línea, Alejandra Auer, Néstor Maceira y Claudia Mikkelsen estudian el proceso de agriculturización en partidos de la Cuenca Mar Chiquita, localizados en Buenos Aires (Argentina). Para ello, analizan la variación de varios indicadores sobre variables que los caracterizan. Sus resultados muestran dos patrones en el proceso de agriculturización: cambios en la dimensión socio-demográfica y cambios en la dimensión económico-productiva. Ello les permite concluir solicitando una mirada integral de los procesos territoriales que evidencien su incidencia en la vulnerabilidad del sistema.

Desde un enfoque basado, también, en el análisis paisajístico, Arturo García Romero, Manuel Antonio Serrano, Alberto Méndez Méndez y Eduado Salinas Chávez proponen, en un estudio desarrollado en Atlautla (México), una metodología para identificar y evaluar atractivos turísticos basada en su calidad paisajística y su viabilidad social. Dicha metodología permitió, por un lado, 
identificar 29 atractivos turísticos, incluyendo 7 de alta calidad paisajística y preferencia, y, por otro lado, concluir que la comunidad carece de una adecuada capacidad organizativa.

Continuando con los análisis del paisaje, Joan Nogué, Jordi de San Eugenio y Pere Sala analizan los indicadores de paisaje implementados por el Observatorio del Paisaje de Cataluña (España), haciendo hincapié en el despliegue de indicadores intangibles. Su trabajo supone una apuesta inédita en Europa en el establecimiento de una catalogación de los valores inmateriales de un paisaje por parte de un ente público. Los autores concluyen recomendando la implantación de un conjunto de indicadores al sistema de toma de decisiones relacionado con las políticas paisajísticas.

Considerando los paisajes remotos con alto valor patrimonial, Gerardo Saelzer Canouet, Marcela Soto y Luis Álvarez, desarrollan un interesante trabajo en un espacio próximo al Parque Nacional de Torres del Paine (Chile). Los autores analizan las demandas locales y globales en campos del patrimonio natural y planificación enfocada en turismo receptivo utilizando una metodología basada en levantamiento de conflictos en el área de estudio. Sus resultados cuestionan el Plan Seccional como herramienta de desarrollo territorial eficaz en situación remota, evidenciando que un espacio especial necesita una planificación excepcional y particular, antes que una clásica y generalista de territorios bajo procesos de urbanización consolidados.

Por último, Enrique Aliste, Beatriz Bustos, Daniella Gac y Raphael Schirmer examinan los discursos del sector vitivinícola en las viñas del Valle Central (Chile) para identificar el rol que juega el paisaje y los territorios del vino en su comercialización. Los autores identifican cinco elementos predominantes: tradición, vínculo europeo, terroir, medio ambiente y exclusividad; y concluyen que el concepto de terroir excluye a los trabajadores y habitantes de los espacios vitivinícolas, de modo que podría ser un concepto más asociado hacia los mercados de destino que un concepto con contenido de identidad local y territorial, distanciándose de las condiciones locales.

Revista de Geografía Norte Grande también publica, como es habitual, trabajos que abordan temáticas asociadas a diferentes campos de la geografía. En este caso, uno de ellos, más ligado a la geografía física, acomete un importante estudio sobre la distribución espacial de plagas en ecosistemas agrícolas de Chile; mientras, otros tres, más relacionados con la geografía humana y la ordenación territorial, discuten problemáticas de significativa actualidad. Uno de ellos trata temas asociados a la inmigración en ciudades europeas; otro, aborda el impacto que tuvo en diferentes regiones de la Unión Europea la crisis financiera mundial de 2008; y un último trabajo, estudia la producción científica española en América Latina y el Caribe.

La distribución espacial de plagas, en este caso representadas por artrópodos, en ecosistemas agrícolas de la Región de Coquimbo (Chile) es un tema abordado por Jaime Pizarro Araya, Fermín Alfaro, Rodrigo Muñoz-Rivera, Juan Barriga Tuñón, Luis Letelier y Carlos Tirado. Los autores analizan la distribución espacial de la riqueza de artrópodos de importancia económica mediante una exhaustiva revisión de bases de datos históricas, colecciones, literatura y colectas entomológicas. Los resultados mostraron que la riqueza y los registros espaciales se agruparon mayoritariamente en superficies de mayor actividad agrícola. Como conclusión, los autores esperan que sus resultados sirvan como información base para entender la estructura de la riqueza de plagas en áreas agrícolas fuertemente modificadas. 
El estudio desarrollado por Gwendoline De Oliveira Neves, Claudia Hurtado Rodríguez y Ricardo Iglesias Pascual plantea la importante cuestión de si el migrante se integra o se inserta. Para ello, los autores analizan las variaciones espaciales o cambios en la localización residencial de la población inmigrante en dos áreas metropolitanas, Málaga y Almería (España) durante el periodo 2003-2013. Los resultados muestran la inserción como modelo de incorporación a la ciudad predominante. No obstante, al ser una inserción meramente residencial, los autores concluyen que suele derivar en la estigmatización socio-territorial de los barrios donde se concentra el inmigrante, dificultando su adecuada integración y plena incorporación a la sociedad de acogida.

El impacto de la crisis financiera de 2008 en diferentes regiones de la Unión Europea (UE) es abordado por María Antonia Martínez Caldentey e Iván Murray Mas en un excelente artículo de aplicación geográfica. Los autores estudian el impacto de dicha crisis en la UE y reflexionan sobre el propio proceso de construcción de una UE a múltiples velocidades. Para ello, utilizan enfoques como la teoría del Desarrollo Geográfico Desigual, y aplican técnicas de análisis espacial, combinando análisis factorial y clúster a escalas espaciales regionales. Los autores observan que con la crisis se ha enfatizado el desarrollo geográfico desigual en el seno de la UE y concluyen haciendo hincapié en el papel que la geografía debe jugar para corregir las desigualdades.

Por último, la producción científica española en la geografía de los países de América Latina y el Caribe es abordada por Francisco Cebrián Abellán y Carmen Delgado Viñas. Para ello, los autores identifican, por una parte, los artículos de investigación editados en las revistas de Geografía y por otro lado las tesis doctorales. Los resultados muestran cómo se ha producido un incremento y diversificación en España de la producción científica en Geografía que trata sobre los países latinoamericanos. Además, ha permitido identificar cómo ha evolucionado el número de trabajos, las disciplinas y territorios que han tenido un protagonismo mayor, así como los efectos de las diferentes coyunturas y estrategias institucionales en relación con los países hispanoamericanos.

Como cierre de este número 72, se publica una reseña bibliográfica llevada a cabo por Antoine Bailly, Alejandro Salazar y Andrés Núñez, que lleva por nombre “Viaje por la Geografía. Una geografía para el mundo. Una geografía para todo el mundo", en la que los autores destacan que este excelente libro puede aproximarnos a variadas temáticas espaciales, que condensan múltiples prácticas sociales, diversidad de lógicas e intereses en pugna y variadas definiciones legítimas de los sentidos sociales de la espacialidad. 
